\title{
Supercritical Carbon Dioxide Extraction of Hevea Brasiliensis Seeds: Influence of Particle Size on to Oil Seed Recovery and its Kinetic
}

\author{
Lee Nian Yian ${ }^{a}$, Nicky Rahmana Putraa ${ }^{a}$ Zuhaili Idham ${ }^{a}$, Nor Faadila Mohd \\ Idrus $^{a}$, Ahmad Hazim Abdul Aziz ${ }^{a}$, Siti Hamidah Mohd Setapar ${ }^{b}$, Mohd Azizi \\ Che Yunus ${ }^{a, *}$
}

${ }^{a}$ Centre of Lipid Engineering and Advanced Research (CLEAR), Ibnu Sina Institute for Scientific and Industrial Research, Universiti Teknologi Malaysia, 81310, UTM Johor Bahru, Malaysia; ${ }^{b}$ Department of Chemical Process Engineering, Malaysia-Japan International Institute of Technology, Universiti Teknologi Malaysia 54100 Kuala Lumpur, Malaysia
*For correspondence: azizi@cheme.utm.my

Received: 29 Nov 2020

Accepted: 25 June 2021

(C) Copyright Yian. This article is distributed under the terms of the Creative Commons Attribution License, which permits unrestricted use and redistribution provided that the original author and source are credited.
Abstract The aim of this study is to investigate the effect of particle sizes on yield, diffusivity, mass transfer and morphological characterization on extraction rate of rubber seed oil recovery by supercritical carbon dioxide $\left(\mathrm{ScCO}_{2}\right)$. Pressure $30 \mathrm{MPa}$, temperature $60^{\circ} \mathrm{C}$ and average particle size $500 \mu \mathrm{m}$ gives the maximum oil recovery $(34.71 \%)$, diffusivity coefficient $(5.13 \mathrm{E}-12 \mathrm{~m} 2 / \mathrm{s})$ and extraction rate $(0.6 \mathrm{mg} / \mathrm{sec})$. The morphological characterization of extracted rubber seeds was done on the basis of scanning electron microscopy which was parallel with the results of the effect of particle size. The results obtained from gas chromatography-mass spectrometry showed that the rubber seeds oil contained significant essential fatty acids and certain chemical constituents which are very valuable.

Keywords: Rubber seeds oil, Supercritical carbon dioxide, Particle size, Mass transfer, Morphological characterization

\section{Introduction}

Rubber tree, a plant belonging to the family of Euphorbiaceae, the genus is Hevea while the species of rubber is brasiliensis. Rubber tree is very well-known in producing natural rubber or latex which is very useful in industries and daily lives subsequently the rubber seeds had been discarded and wasted in huge amount. However, there is a rich existence of fatty acids especially alpha-linolenic acid (omega-3), oleic acid (omega-9) and linoleic acid (omega-6) in the rubber seed oil [1]. Both omega-3 and omega-6 polyunsaturated fatty acids (PUFA) are precursors of hormone like compounds known as eicosanoids, which are important biological processes in the human body [2]. Omega-3 fatty acids are considered as essential for normal growth and development throughout life cycle [3].

Traditionally, solvent extraction, hydraulic pressing and expeller pressing are frequently used in combination for the extraction of oilseeds. Among these methods, solvent extraction is the most efficient method for pressing oilseeds. However, environmental issues such as global warming, industrial waste pollution and over-load of hazardous materials have become highly concerned by the society. In addition, the increasing of health public awareness and most of the customers prefer natural products mainly in the food and cosmetic sectors [4], researchers are seeking the solutions to reduce the environmental impacts and produce higher quality of products. As a result, supercritical fluid extraction had been chosen 
to be an alternative to extract the oilseeds. Supercritical fluid technology is green separation process because it does not use any organic solvent with higher quality and purity.

Supercritical carbon dioxide extraction is preferable chosen due to their high diffusivity and low viscosity [5]. According to Starmans and Nijhuis [6], no component with critical parameters as mild as carbon dioxide which shows that the extraction can be conducted in very low temperature and do not cause adverse effect to the physicochemical properties of the extract. For food commodities, $\mathrm{CO}_{2}$ is chosen due to inert, non- flammable and environmentally friendly [7]. In addition, there is no organic solvent residual inside the extracted sample since carbon dioxide is in gas form at room temperature. Hence, supercritical carbon dioxide plays significant role in many different industries such as pharmaceutical, natural product, food, environmental and cosmetics. Recently, supercritical fluid extraction had been studied by many researches in different aspect. The recent applications of $\mathrm{ScCO}_{2}$ extraction are to concentrate minor constituents from various oilseeds such as extraction of grape seeds oil [8], flaxseed [9], Echium vulgare seed oil [10], roselle seed [11], passion fruit seed oil [12], Camelina sativa seeds [13] and other applications. However, there are very few reported study regarding the extraction of rubber seed oil as a waste using supercritical carbon dioxide.

Furthermore, compactness and oily raw material is one of problems in the of rubber seed oil recovery. Therefore, variable of particle size is one of significant factors on the extraction process. Application of single sphere model and Esquivel model is one of prominent methods to determine diffusivity and mass transfer process on the particle size. Therefore, the objective of this study is to investigate the effect of particle sizes on yield, diffusivity and extraction rate of rubber seed oil recovery. In addition, the identification of essential fatty acids was studied using gas chromatography-mass spectrometry while the scanning electron microscope was used to characterize the morphology of rubber seeds after extraction.

\section{Experimental}

\section{Sample preparation}

The fresh rubber (Hevea brasiliensis) seeds $(2 \mathrm{~cm} \times 3 \mathrm{~cm}$, spherical, light yellow) were obtained from local company, NDI UTARA, Kepala Batas, Kedah, Malaysia. The outer layer of the fresh seeds was separated from the shell via crushing, rinsed with distilled water and sliced into small pieces. The seeds were oven dried (Memmert, Germany) at $105^{\circ} \mathrm{C} \pm 2^{\circ} \mathrm{C}$ to avoid possible environmental contamination and to ensure consistent drying process. The dried seeds were ground (Werke, Germany) and sieved to average particle sizes of 500,355 and $250 \mu \mathrm{m}$. The ground seeds were stored in air tight containers and kept in the freezer at temperature about $-20^{\circ} \mathrm{C}$ to preserve the volatile sample and maintain the freshness of the seeds.

\section{Chemical preparation}

All the analytical grade reagents such as n-hexane (Merck, Selangor, Malaysia), sodium methoxide solution (Sigma-Aldrich, Selangor, Malaysia) and 95\% carbon dioxide (Kras Instrument and Services, Johor, Malaysia) were used in the experiments.

\section{Supercritical carbon dioxide extraction assisted by ethanol}

The supercritical carbon dioxide $\left(\mathrm{SC}-\mathrm{CO}_{2}\right)$ unit has a programmable back pressure regulator (Model BP2080, JASCO, Japan) and HPLC pump (Jasco, Japan), which controls the pressure by changing the time interval between the valve opening and closing instead of controlling the pressure using the gap between a valve seat and the oscillating spindle. Hence, the extracted components were forced against the valve, thus reducing the possibility of blockage of the flow pass. The schematic diagram of the supercritical carbon dioxide extraction unit is shown in Fig. 1.

The supercritical carbon dioxide extraction of rubber seed oil was performed using the dynamic extraction method. Approximately $5 \mathrm{~g}$ of dried rubber seeds were used for each extraction. The $\mathrm{CO}_{2}$ pump was set at the flow rate, temperature and pressure combinations as shown in Table 1. The extraction was started by opening the pump valve and BPR valve (V2 \& V5 in Fig. 1). The BPR valve was regulated to allow the $\mathrm{CO}_{2}$ to flow together with the extracted oil through the restrictor upon reaching the required pressure. 


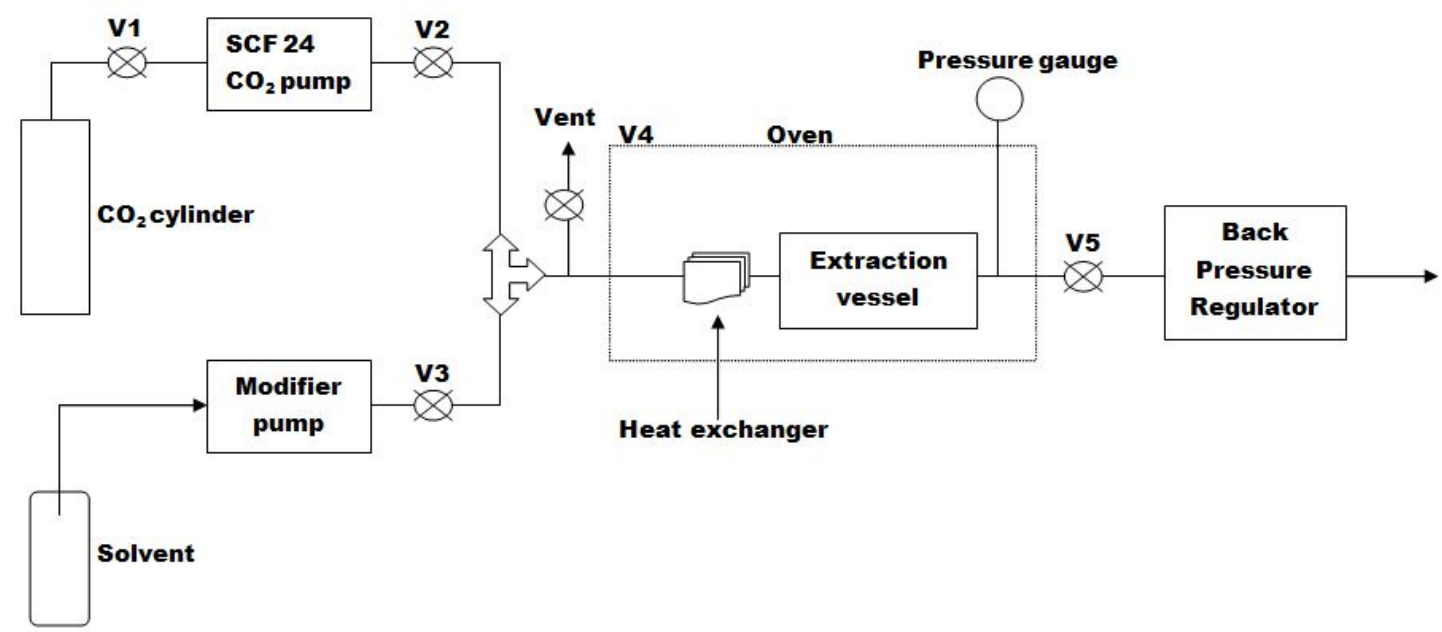

Fig. 1. The schematic diagram of SFE unit

\section{Calculation of oil yield recovery}

The oil yield recovery was calculated using the following Eq. (1),

$$
\text { Oil yield recovery }(\%)=\frac{m_{a}}{m_{a b}} \times 100 \%
$$

where $m_{a}$ is mass of the extract in gram and $m_{a b}$ is mass of sample in gram.

\section{Modelling}

\section{Empirical modeling}

Modified Esquivel model by Putra, Idham [14] has been used to obtain mass transfer value $(\mathrm{g} / \mathrm{sec})$ between $\mathrm{ScCO}_{2}$ and rubber seed oil. The equation has been given following equation:

$$
Y_{t}=Y_{2}\left(\frac{t}{k_{2}+t}\right)
$$

Where $Y_{t}$ is the predicted mass of oil yield recovery $(\mathrm{g})$, while $Y_{2}(\mathrm{~g})$ is mass of oil yield recovery $(\mathrm{g}), k_{2}$ $(\mathrm{sec})$ is the adjustable parameters and $Y_{2} / k_{2}$ is the extraction rate $(\mathrm{g} / \mathrm{sec})$.

\section{Kinetic Modelling}

Single sphere model by Crank [15] is commonly used to determine diffusivity of extraction process due to less adjustable parameters. The diffusion coefficient was obtained by Equation (3).

$$
\frac{M_{t}}{M_{\infty}}=1-\frac{6}{\pi^{2}} \sum_{n-1}^{\infty} \frac{1}{n^{2}} \exp \frac{D_{e} t^{2} \pi^{2}}{R^{2}}
$$

Where $M t$ is the mass of oil recovery at time $(\mathrm{g}), \mathrm{M}_{\infty}$ is the mass of oil recovery after infinite time $(\mathrm{g}), D_{e}$ is diffusivity $\left(\mathrm{m}^{2} / \mathrm{sec}\right), \mathrm{R}$ is radius of average particle size $(\mathrm{m})$, and $t$ is time $(\mathrm{sec})$.

\section{Statistical analysis}

Average absolute relative deviation (AARD) and coefficient of determination $\left(R^{2}\right)$ was used to determine the best suitable model between model and experimental data. The equation is as follows:

$$
A A R D(\%)=\frac{1}{n} \sum_{i=1}^{n}\left|\frac{Y_{\text {model }}-Y_{\text {exp }}}{Y_{\text {exp }}}\right|
$$

where $Y_{\text {model }}$ is the oil yield recovery of the model data $(\mathrm{g}), Y_{\text {exp }}$ is the oil yield recovery of the experimental data $(\mathrm{g})$ and $\mathrm{n}$ is number of experimental data points. The equation of $R^{2}$ is shown as Eq. (5) 


$$
R^{2}=1-\frac{\sum_{i}\left(y_{i}-f_{i}\right)^{2}}{\sum_{i}\left(y_{i}-\bar{y}\right)^{2}}
$$

Where, $\sum_{i}\left(y_{i}-f_{i}\right)^{2}$ is the residual data as error of model correlated the experimental data and $\sum_{i}\left(y_{i}-\bar{y}\right)^{2}$ is the variance of the data.

\section{Characterization of rubber seeds surface after extraction}

The morphology of the rubber seeds after extraction was studied using low vacuum scanning electron microscope (JEOL JSM-6390LV). The samples for this study were coated with Platinum (PT) using auto fine coater (JEOL JFC-1600).

\section{Gas chromatography-mass spectrometry (GC-MS) analysis of rubber seed oil}

About $0.05 \mathrm{~mL}$ of extracted oil was added with $0.5 \mathrm{~mL}$ sodium methoxide ( $\mathrm{NaOMe}, 1 \mathrm{M})$ in $0.5 \mathrm{~mL}$ hexane. The condition prepared to be alkali-catalyzed methylation to convert the extracted oil to fatty acid methyl esters (FAME). The assay of FAME was carried out with GC-MS from Perkin-Elmer (Norwalk, CT) by electron ionization (EI) at $70 \mathrm{eV}$, scanning with $40 \mathrm{amu}-700$ amu and acceleration voltage of 1650 volt. The column used was HP-5MS (Hewlett Packard, USA) with the dimensions of $30 \mathrm{~m} \times 0.25 \mathrm{~mm}$ I.D., film $0.5 \mathrm{~mm}$ ). The helium as the carrier gas was set at a flow rate of $1.0 \mathrm{~mL} / \mathrm{min}$. The injection volume of sample was $1 \mu \mathrm{L}$; the temperature of injector and interface were set at $250^{\circ} \mathrm{C}$ and $320^{\circ} \mathrm{C}$, respectively. Meanwhile, the column temperature was at $150^{\circ} \mathrm{C}$ initially for $5 \mathrm{~min}$, then increased to $250^{\circ} \mathrm{C}$ for $8 \mathrm{~min}$.

\section{Results and discussion}

\section{Effect of particle size}

Previous studies revealed that oil recovery increased when the reduction of particle size of the sample feed [16]. This is because the accessible of the solvent to the sample matrix is favourable due to the increase of surface area reducing the mass transfer resistance. On the other hands, the larger the sample matrix will have smaller surface area causing the resistance of mass transfer and reduce the extraction yield.

However, the extraction of rubber seeds oil was contrast with the recent studies. Fig. 2 shows that the rubber seeds with bigger particle size of $500 \mu \mathrm{m}$ produce highest oil yield even though the operating conditions are constant with difference pressure of $20 \mathrm{MPa}$ and $30 \mathrm{MPa}$. The reason behind is the nature of the rubber seeds is very oily and sticky; as a result, the particle size is reduced, the sample become stickier and bind together causing the space between the sample matrix very compact (references). Consequently, surface area become smaller and the $\mathrm{CO}_{2}$ that diffused through the sample experience higher mass transfer resistance thus decreasing the extraction oil yield.

According to Bimakr, Rahman [17], even though fine powder with smaller particle size can speed up the extraction but it may also cause the difficulties in maintaining a proper flow rate in order to get the good optimization of SC-CO2 extraction. The Foeniculum vulgare volatile oil from fennel fruits by $\mathrm{SC}-\mathrm{CO}_{2}$ showed that a small decrease in total oil yield with decreasing the particle size of $0.35 \mathrm{~mm}$ compared to 0.55 and $0.75 \mathrm{~mm}$ [18]. However, most of the findings showed that samples with smaller particle size will give higher oil yield due to the larger surface area for the contact of solvent and samples and also decrease the diffusion path. The extraction of safflower seed oil by supercritical $\mathrm{CO} 2$ showed that the smaller the particles, the greater the effective fluid-solid contact area, the higher the extraction rate, larger particles do not have sufficient quantity or surface area of easily accessible oil causing lower oil yield [19]. Moreover, the study by Al-Rawi, Ibrahim [20] reported that nutmeg oil recovery was increased with a reduction in the particle size due to the larger surface area; as a result the broken of particle cells increases directly compared to the undamaged cells; thus, the oil will be more accessible to the solvent. In addition, separation of the oil from palm kernel matrix using supercritical carbon dioxide examines the effect of different particle size $(\leq 106, \leq 150, \leq 180, \leq 250$ and $\leq 450 \mu \mathrm{m})$ on the oil yield, which are highest oil yield removed was $9.26 \mathrm{~g}$ oil/ $100 \mathrm{~g}$ sample at condition of the particle size of $\leq 150 \mu \mathrm{m}$. The increment of oil yield is due to the larger surface area contact between solvent and palm kernel cake [21]

\section{Single sphere model}

The main assumption of this model is the effect of particle size gives the significant impact on the diffusivity process, thus the oil recovery will directly increase [22]. Fig. 3 and Table 1 show the model has successfully fitted the data with low percentage AARD $(<25 \%)$ at pressure of 20 and $30 \mathrm{MPa}$, temperature of $60{ }^{\circ} \mathrm{C}$. Average particle size $500 \mu \mathrm{m}$ gives the highest diffusivity coefficient of $\mathrm{CO}_{2}(5.13$ $\mathrm{E}-12 \mathrm{~m}^{2} / \mathrm{s}$ ) at pressure of $30 \mathrm{MPa}$, temperature of $60^{\circ} \mathrm{C}$. The lowest diffusivity coefficient of $\mathrm{CO}_{2}$ was 
$2.06 \mathrm{E}-13 \mathrm{~m}^{2} / \mathrm{s}$ at pressure of $20 \mathrm{MPa}$, temperature of $60^{\circ} \mathrm{C}$ and particle size of $250 \mu \mathrm{m}$. The higher average particle size gives the high percentage of oil recovery and diffusivity coefficient at lowest and highest pressure, whereas it indicates the high mass transfer process between the solvent and solute. Therefore, it will increase the kinetic transfer of extract to dissolve into the solvent $[9,23]$. The lowest particle size gives lowest of diffusivity coefficient of supercritical carbon dioxide. It indicates difficulty of solvent to penetrate the rubber seed surface. This is due to compactness of raw material reduce the contact surface of solute-solvent; hence the diffusivity will reduce.

\section{Modified Esquivel model}

Modified Esquivel model was applied to determine the mass transfer of extraction. The benefit of using Esquivel model is two adjustable parameter, thus the model easily fit the experimental data [14]. In this study, Table 1 shows the modified Esquivel model fitted the rubber seed oil recovery. The range of calculated mass transfer on rubber seed oil recovery was 0.02 to $0.6 \mathrm{mg} / \mathrm{sec}$ with average AARD (\%) 15.98, respectively. Fig. 4 also shows the Esquivel model fitted the rubber seed oil at pressure of 20 to $30 \mathrm{MPa}$, temperature of $60{ }^{\circ} \mathrm{C}$ and average particle size 250 to $500 \mu \mathrm{m}$. The coefficients of correlation $\left(R^{2}\right)$ between the model and experimental data were significant $\left(R^{2}>0.70\right)$.

Table 1 shows higher pressure condition increased the extraction rate of rubber seed oil due to the high density of $\mathrm{CO}_{2}$ at temperature of $60^{\circ} \mathrm{C}$ and constant average particle size of 250,355 and $500 \mu \mathrm{m}$. Thus, there are much particle of $\mathrm{CO}_{2}$ to interact the solute [24]. Increasing of density also increases the solubility of extract to soluble in solvent [25]. Increasing of average particle size also increase the mass transfer of the solute-solvent. This is similar trends to previous study that increasing of average particle size of 250,355 and $500 \mu \mathrm{m}$ enhances the oil recovery with high diffusivity and mass transfer. This due to compactness of raw material reduce the contact surface of solute-solvent

\section{Morphology of rubber seeds after extraction}

The results of the supercritical carbon dioxide extraction of rubber seed oil in order to determine the best particle size showed that the rubber seeds with $500 \mu \mathrm{m}$ gave the highest oil yield followed by the rubber seeds with $355 \mu \mathrm{m}$ and $250 \mu \mathrm{m}$. The different of the surface or the characteristics of the rubber seeds after extraction are not easily differentiated with the naked eye [26]. From the SEM micrographs shown in Fig. 5, it can be observed that morphological characteristics are much different between the rubber seeds with different particle size even though the extraction conditions are the same.

The SEM micrograph of Fig. 5 (a) shows clearly that the extracted rubber seeds with particle size 500 $\mu \mathrm{m}$ had shrink to smaller size and there is the broken of the cell wall and shrinkages of the cell compared to the extracted rubber seeds with particle size of $355 \mu \mathrm{m}$ and $250 \mu \mathrm{m}$. Meanwhile, the Fig. 5 (b) show that there is no obvious shrinkage of the cell but still stick together in the cell, less broken of cell walls. Therefore, in this study of supercritical carbon dioxide extraction of rubber seed oil, the bigger particle size gave highest yield had been supported by the SEM morphology of the extracted rubber seeds. The extraction rubber seeds with smaller particle sizes are not favourable compared to the bigger particle size but need to depend on the nature of the raw materials used.

Table 1 Correlation data of single sphere model and Esquivel model fitted rubber seed oil

\begin{tabular}{|c|c|c|c|c|c|c|c|c|c|c|}
\hline \multirow[b]{2}{*}{$\mathrm{P}(\mathrm{MPa})$} & \multirow{2}{*}{$\begin{array}{c}\mathrm{T} \\
\left({ }^{\circ} \mathrm{C}\right)\end{array}$} & \multirow{2}{*}{$\begin{array}{c}\mathrm{FcO}_{2} \\
(\mathrm{~mL} / \mathrm{min})\end{array}$} & \multirow{2}{*}{$\underset{(\mu \mathrm{m})}{\mathrm{dp}}$} & \multicolumn{4}{|c|}{ Esquivel Model } & \multicolumn{3}{|c|}{ Single Sphere Model } \\
\hline & & & & $\begin{array}{l}\text { Yield } \\
(\mathrm{g})\end{array}$ & $\begin{array}{c}\mathrm{Y}_{2} / \mathrm{k}_{2} \\
(\mathrm{mg} / \mathrm{s})\end{array}$ & $\begin{array}{c}\text { AARD } \\
(\%)\end{array}$ & $R^{2}$ & $\begin{array}{l}\text { Diffusivity } \\
\left(\mathrm{m}^{2} / \mathrm{s}\right)\end{array}$ & $\begin{array}{c}\text { AARD } \\
(\%)\end{array}$ & $R^{2}$ \\
\hline 20 & 60 & 4 & 250 & 0.26 & 0.02 & 20.02 & 0.97 & $2.06 \mathrm{E}-13$ & 20.58 & 0.93 \\
\hline 30 & 60 & 4 & 250 & 0.59 & 0.132 & 12.39 & 0.98 & $6.71 \mathrm{E}-13$ & 12.73 & 0.96 \\
\hline 20 & 60 & 4 & 355 & 0.26 & 0.072 & 7.01 & 0.98 & $2.08 \mathrm{E}-12$ & 9.06 & 0.98 \\
\hline 30 & 60 & 4 & 355 & 0.99 & 0.142 & 27.13 & 0.98 & $1.81 \mathrm{E}-12$ & 20.71 & 0.91 \\
\hline 20 & 60 & 4 & 500 & 1.02 & 0.23 & 15.70 & 0.97 & $3.01 \mathrm{E}-12$ & 15.19 & 0.95 \\
\hline 30 & 60 & 4 & 500 & 1.46 & 0.60 & 13.63 & 0.98 & 5.13E-12 & 8.59 & 0.97 \\
\hline
\end{tabular}




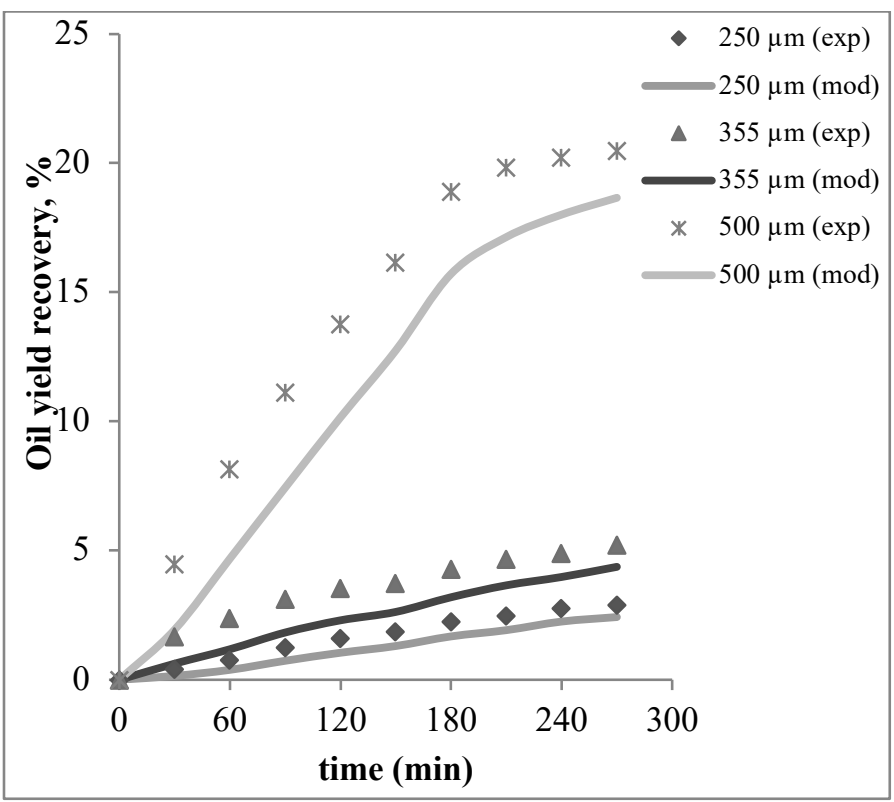

(a)

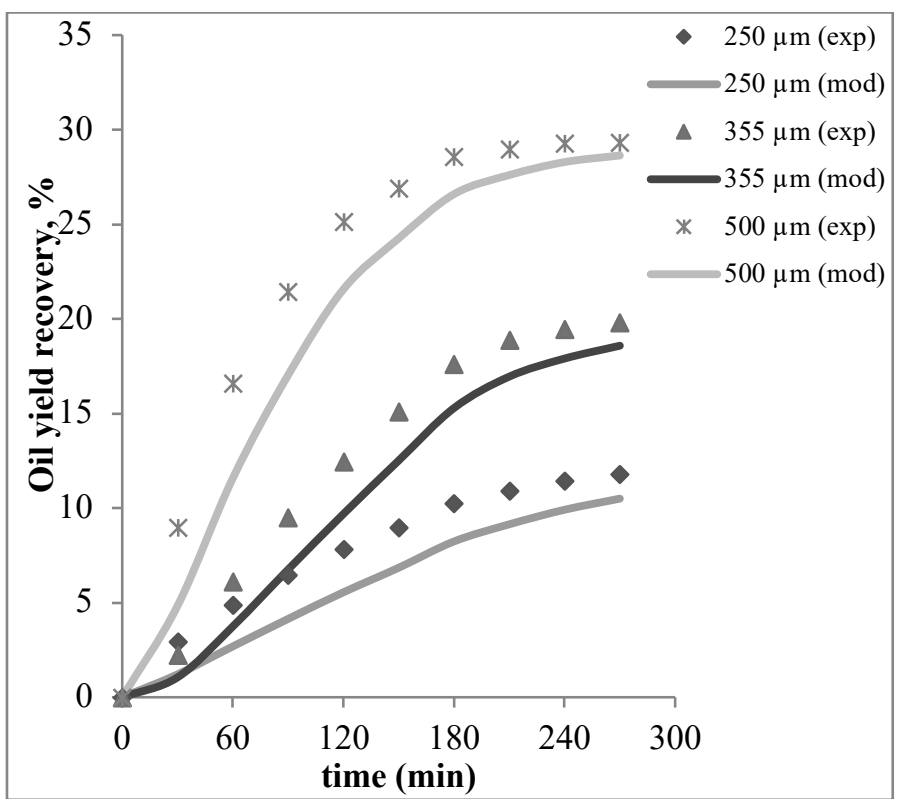

(b)

Fig.3: Single sphere model correlated rubber seed oil yield at condition: a) 30 MPa b) 20 MPa.

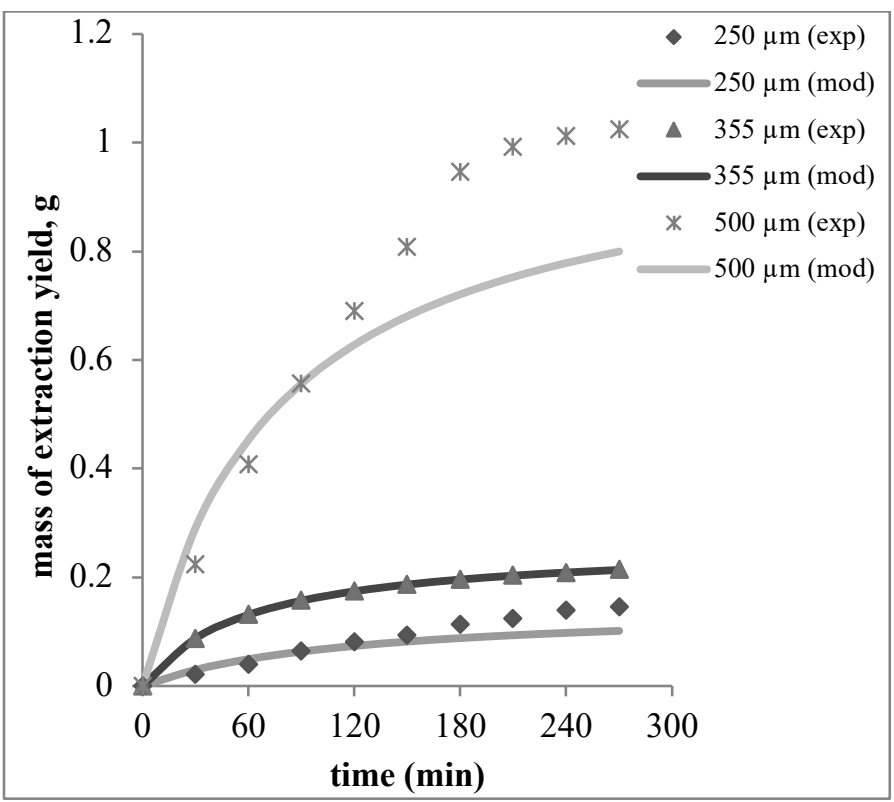

(a)

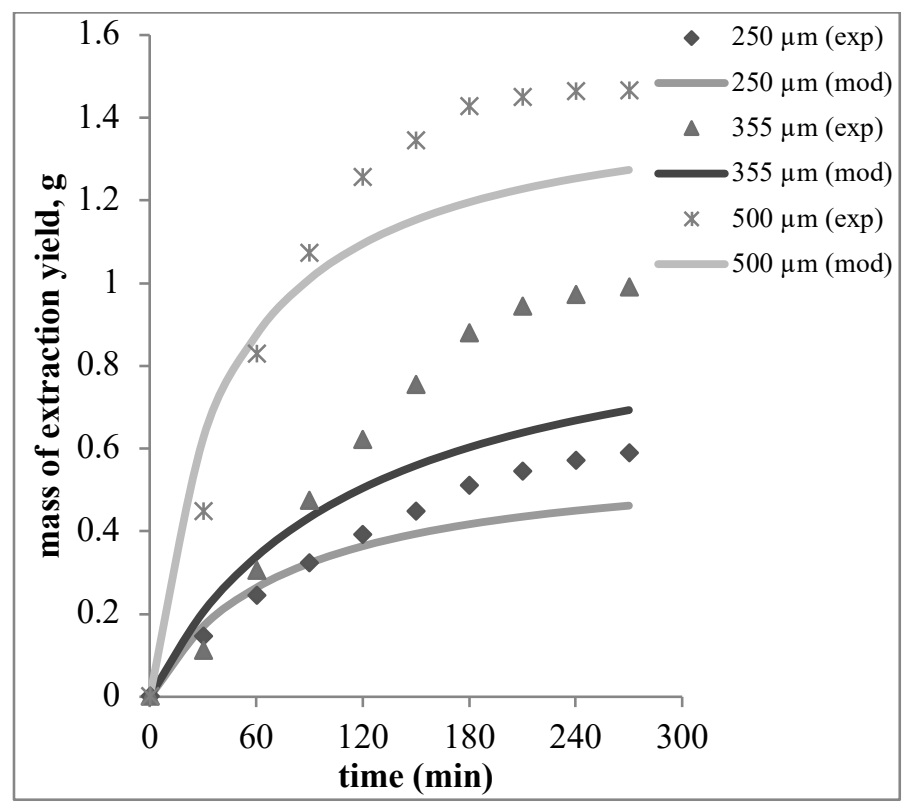

(b)

Fig. 4. Esquivel model correlated rubber seed oil yield at condition: a) $30 \mathrm{MPa}$ b) $20 \mathrm{MPa}$. 

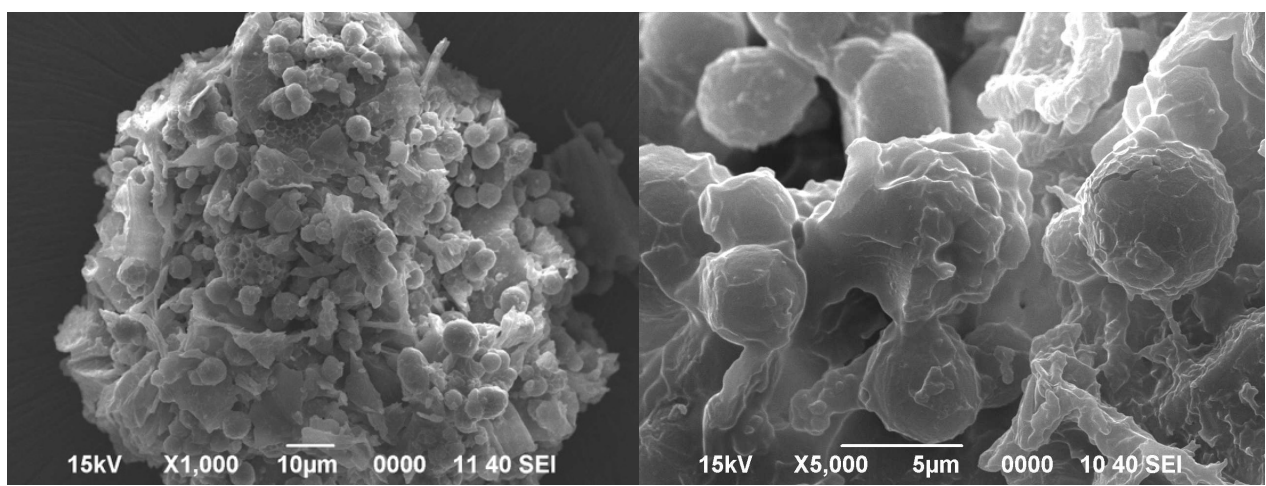

(a)

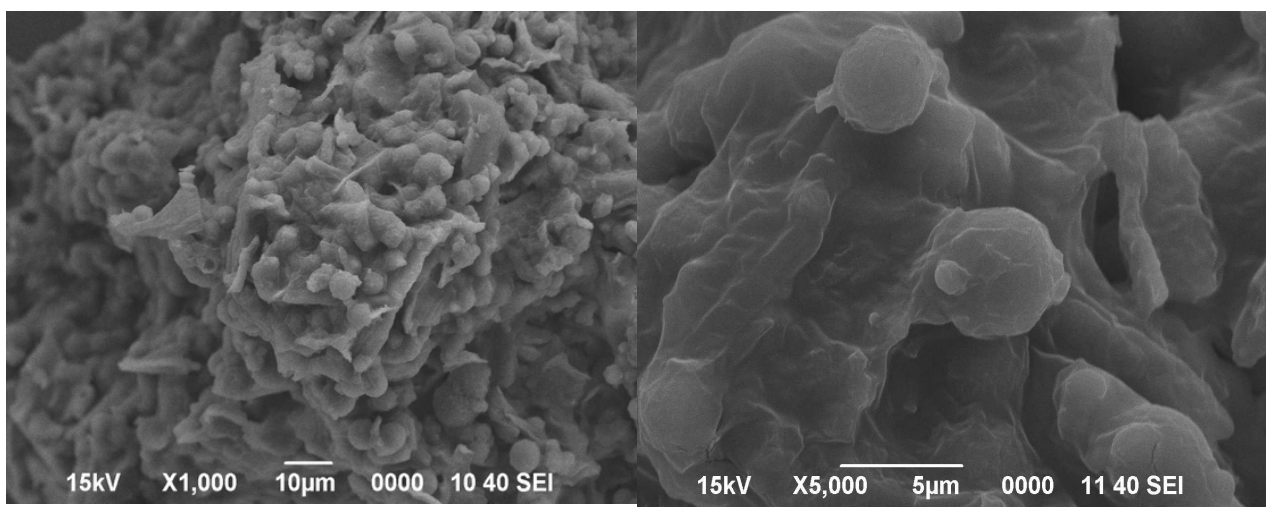

(b)

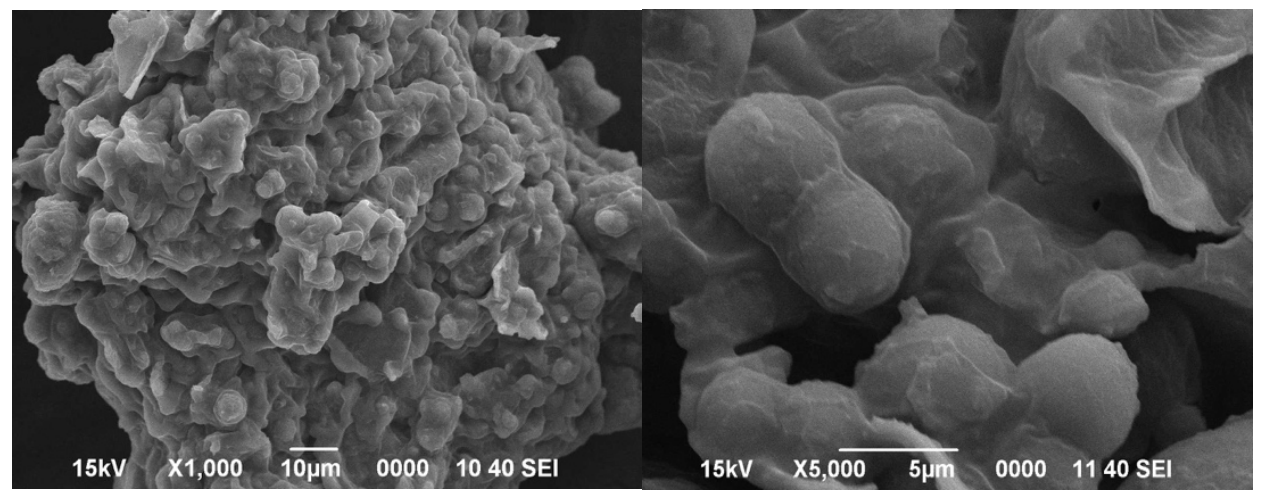

(c)

Fig. 5. SEM Micrograph of rubber seed after extraction with the particle sizes of a) $500 \mu \mathrm{m}$ b) $355 \mu \mathrm{m}$ and c) $250 \mu \mathrm{m}$ respectively.

\section{GC-MS analyses}

The methyl esterification and chemical components in rubber seeds oil were analyzed using GC-MS. The compounds were identified by comparing with standard library of NIST [19]. The Table 2 shows the important chemical constituents and fatty acids in rubber seeds oil.

The 2, 4-decadienal, (E, E) is an aromatic substance found in cooked fish, beef, roasted peanut and butter. This compound has the odour of citrus at low concentration. The fatty acid compositions of rubber seed oil are saturated and unsaturated fatty acid. The palmitic acid is saturated fatty acid and usually applied in soap and cosmetics sectors. In addition, palmitic acid also acts as textile additives. Meanwhile, linoleic acid, oleic acid and $\alpha$-linolenic acid are categorized as unsaturated fatty acids. Even though rubber seed oil contains high amount of linoleic acid, but it also contains significant value of $\alpha$-linolenic acid which is the omega- 3 fatty acid. The $\alpha$-linolenic acid which is the parent compound of the omega- 3 
fatty acids, recently found in soybean, rapeseed and flaxseed oil [27]. Based on the study of Eckert, Franke [28], the deficiency of $\alpha$-linolenic acid will induces the more marked abnormalities in celebral structures than in others as the pituitary gland and frontal cortex are more severely affected. Last but not least, $\alpha$-linolenic acid is very significant for human metabolism, not only acting as precursors to bioactive molecules but also playing structural roles in phospholipid bilayers [29].

Table 2: Important chemical constituents and fatty acids in rubber seed oil

\begin{tabular}{ccc}
\hline RT $(\min )$ & Chemical Compounds & Area (\%) \\
\hline 7.052 & 2,4-decadienal, (E,E) & 0.16 \\
14.353 & palmitic acid & 3.68 \\
16.087 & linoleic acid & 32.98 \\
17.924 & oleic acid & 0.59 \\
19.085 & a-linolenic acid & 1.41 \\
\hline
\end{tabular}

RT: Retention Time

In addition, linoleic acid (omega-6) plays important role in the biosynthesis of arachidonic acid (AA) and abundant in vegetable oils. Linoleic acid is well known of its application in oil paints and varnishes. Furthermore, linoleic acid also has beneficial properties on skin. Moreover, oleic acid (omega-9) is believed can reduce the low-density lipoprotein in human body and reducing the hypertension effects.

\section{Conclusions}

Pressure $30 \mathrm{MPa}$, temperature $60^{\circ} \mathrm{C}$ and average particle size $500 \mu \mathrm{m}$ gives the maximum oil recovery $(34.71 \%)$, diffusivity coefficient $\left(5.13 \mathrm{E}-12 \mathrm{~m}^{2} / \mathrm{s}\right)$ and extraction rate $(0.6 \mathrm{mg} / \mathrm{sec})$. The SEM micrograph also showed that the rubber seeds with bigger particle size has the obvious shrinkage and broken cell walls thus produce highest oil yield. In addition, the optimum extraction time of rubber seed oil was 180 min to obtain the optimum oil yield. The analyses of GC-MS also demonstrate the significant chemical constituents and fatty acids in the rubber seed oil. Therefore, the rubber seed oil has the great potential to be applied in different sectors and developed into different products to transform the waste to wealth and supercritical carbon dioxide is the green and sustainable alternative to extract oilseeds.

\section{Acknowledgement}

The authors gratefully acknowledge Malaysia Government (Escience Fund) Vot 4S020 for the financial support and UTM Iconic Grant Vot Q.J130000.4351.09G56.

\section{References}

[1] Abdullah, B.M. and J. Salimon, Physicochemical characteristics of Malaysian rubber (Hevea brasiliensis) seed oil. European Journal of Scientific Research, 2009. 31(3): p. 437-445.

[2] Shahidi, F. and U.N. Wanasundara, Omega-3 fatty acid concentrates: nutritional aspects and production technologies. Trends in food science \& technology, 1998. 9(6): p. 230-240.

[3] Talab, H.A., et al., Extraction and purification of omega-3 fatty acids concentrate from Hypophthalmichthys molitrix oil. Nutrition \& Food Science, 2010.

[4] Uribe, J.A.R., et al., Extraction of oil from chia seeds with supercritical $\mathrm{CO}_{2}$. The Journal of Supercritical Fluids, 2011. 56(2): p. 174-178.

[5] Hatami, T., M.A.A. Meireles, and O.N. Ciftci, Supercritical carbon dioxide extraction of lycopene from tomato processing by-products: Mathematical modeling and optimization. Journal of Food Engineering, 2019. 241: $p$. 18-25.

[6] Starmans, D.A. and H.H. Nijhuis, Extraction of secondary metabolites from plant material: a review. Trends in Food Science \& Technology, 1996. 7(6): p. 191-197.

[7] Danlami, J.M., et al., A parametric investigation of castor oil (Ricinus comminis L) extraction using supercritical carbon dioxide via response surface optimization. Journal of the Taiwan Institute of Chemical Engineers, 2015. 53: p. 32-39.

[8] Duba, K. and L. Fiori, Supercritical CO2 extraction of grape seeds oil: scale-up and economic analysis. International Journal of Food Science \& Technology, 2019. 54(4): p. 1306-1312.

[9] Özkal, S.G. and M.E. Yener, Supercritical carbon dioxide extraction of flaxseed oil: Effect of extraction parameters and mass transfer modeling. The Journal of Supercritical Fluids, 2016. 112: p. 76-80.

[10] Bilgiç-Keleş, S., et al., Response surface optimization and modelling for supercritical carbon dioxide extraction of Echium vulgare seed oil. Journal of Supercritical Fluids, 2019. 143: p. 365-369. 
[11] Naeem, M.A., H.A. Zahran, and M.M. Hassanein, Evaluation of green extraction methods on the chemical and nutritional aspects of roselle seed (Hibiscus sabdariffa L.) oil. OCL, 2019. 26: p. 33.

[12] dos Santos, L.C., et al., Solubility of passion fruit (Passiflora edulis Sims) seed oil in supercritical CO2. Fluid Phase Equilibria, 2019. 493: p. 174-180.

[13] Belayneh, H.D., et al., Ethanol-Modified Supercritical Carbon Dioxide Extraction of the Bioactive Lipid Components of Camelina sativa Seed. Journal of the American Oil Chemists' Society, 2017. 94(6): p. 855-865.

[14] Putra, N.R., et al., Extraction of peanut skin oil by modified supercritical carbon dioxide: Empirical modelling and optimization. Separation Science and Technology, 2018. 53(17): p. 2695-2703.

[15] Crank, J., The mathematics of diffusion. 1979: Oxford university press.

[16] Aris, N.A., et al., Effect of particle size and co-extractant in Momordica charantia extract yield and diffusion coefficient using supercritical CO2. Malaysian Journal of Fundamental and Applied Sciences, 2018. 14(3): $p$. 368-373.

[17] Bimakr, M., et al., Optimization of Supercritical Carbon Dioxide Extraction of Bioactive Flavonoid Compounds from Spearmint (Mentha spicata L.) Leaves by Using Response Surface Methodology. Food and Bioprocess Technology, 2012. 5(3): p. 912-920.

[18] Coelho, J., et al., Supercritical carbon dioxide extraction of Foeniculum vulgare volatile oil. Flavour and Fragrance Journal, 2003. 18(4): p. 316-319.

[19] Han, X., et al., Extraction of safflower seed oil by supercritical CO2. Journal of food engineering, 2009. 92(4): p. $370-376$

[20] Al-Rawi, S.S., et al., Comparison of yields and quality of nutmeg butter obtained by extraction of nutmeg rind by soxhlet and supercritical carbon dioxide (SC-CO2). Journal of food engineering, 2013. 119(3): p. 595-601.

[21] Rahman, N.N.A., et al., Supercritical carbon dioxide extraction of the residual oil from palm kernel cake. Journal of Food Engineering, 2012. 108(1): p. 166-170.

[22] Putra, N.R., et al., Effect of particle size on yield extract and antioxidant activity of peanut skin using modified supercritical carbon dioxide and soxhlet extraction. Journal of Food Processing and Preservation, 2018. 42(8): p. e13689.

[23] Putra, N., et al. Effects of process parameters on peanut skins extract and CO2 diffusivity by supercritical fluid extraction. in IOP Conference Series: Materials Science and Engineering. 2018. IOP Publishing.

[24] Putra, N.R., et al., Comparison extraction of peanut skin between CO2 supercritical fluid extraction and soxhlet extraction in term of oil yield and catechin. Pertanika Journal of Science \& Technology, 2018. 26(2).

[25] Lee, W.J., et al., Solubility of red palm oil in supercritical carbon dioxide: Measurement and modelling. Chinese Journal of Chemical Engineering, 2017.

[26] Degano, C., et al., Seed characterization and scanning electron microscope (SEM) morphology of the testa of three groups of Argentine Opuntia ficus-indica (Cactaceae). J. PACD, 1997. 2: p. 103-113.

[27] Rubio-Rodríguez, N., et al., Production of omega-3 polyunsaturated fatty acid concentrates: a review. Innovative Food Science \& Emerging Technologies, 2010. 11(1): p. 1-12.

[28] Eckert, G.P., et al., Plant derived omega-3-fatty acids protect mitochondrial function in the brain Pharmacological research, 2010. 61(3): p. 234-241.

[29] Venegas-Calerón, M., O. Sayanova, and J.A. Napier, An alternative to fish oils: metabolic engineering of oilseed crops to produce omega-3 long chain polyunsaturated fatty acids. Progress in lipid research, 2010. 49(2): p. 108-119. 